\title{
Cartoon Art Genres as Catalyst of Social Revolution: A Critique
}

\author{
Alimi, Adesola Olutoyin \\ Department of Art, Design and Printing Technology, The Polytechnic, Ibadan, Nigeria \\ Adeniji, Julianah Bolade \\ Department of Art, Design and Printing Technology, The Polytechnic, Ibadan, Nigeria
}

\begin{abstract}
The thematic content and the functional value of cartoons are essentially expedient to achieve effective communication, especially in modern society. Cartooning is an art form which thrives on humour and satire. It is a popular mode of communication online and in the print media in Nigeria. The content of the cartoon message is a function of variables such as political, economic, education, socio-cultural, media and domestic matters. Functionally, cartoons are a means of criticizing undesirable behaviour pattern of individuals, groups and policies of the government, a source of entertainment and a diary of significant events. The formulation of the cartoon message is, therefore, a response to the needs of society. This study seeks to examine the influence of cartoon communication in the process of social revolution given the nature of volatility of today's society. Findings revealed that cartoon could communicate best if the quality of social education is encouraged at formal and informal levels. It is also recommended that cartoon artists should maintain a balance between their contents and the reading audience to engage issues and policies in the most beneficial way.
\end{abstract}

Keywords: Cartoon, Social revolution, Catalyst, Art genres.

DOI: $10.7176 / \mathrm{ADS} / 74-03$

Publication date:June $30^{\text {th }} 2019$

\section{Introduction}

Cartooning is a form of non-verbal communication which transcends the basic and essential content of any given message, owing to its persuasive and strong influence with a compelling appeal to the psychology of the targets (Alimi, 2004). This is further corroborated by Parkinson, (2011) who posits that visual language has the potential for increasing human bandwidth-the capacity to take in, comprehend and more efficiently synthesize a large amount of new information. As humans, we attempt to interpret the stimuli we are exposed to and so actively explore, select and organize these stimuli, which in turn affect the way we recognize and perceive what we see. (Alimi, 2004).

Over time, cartoons had featured in newspapers and magazines published the world over. Other media are the internet, social media, print and electronic media. Cartoonists are a rare breed of artists with a particular passion for developing or evolving a style that is unique to their emotional and psychological disposition. Their style of mood expression is most significant to the mood of the news item being projected through caricature illustrations. The cartoon artists intend to capture the feelings of a news item in the most accurate way to evoke an emotional reaction from the primary targets of such news item.

The Encyclopedia Britannica explains that cartoon, which is derived from Italian 'Catone' which means 'paper' referred to a preliminary sketch for a large canvas or fresco painting for architectural drawing. Most caricature arts was used to correct political and legislature abuses, as well as ridicule the royalty family in Britain, according to historical accounts. Cartoons generally serve as comic relief that breaks the burden of depression commonly suffered by most readers of newspapers usually stocked by socio-political hurricanes in the nation. (Bertoline et al. 1998). A cartoon is a significant source of humour providing a mixture of entertainment and education to newspaper readers who have become naturally attracted to its peculiar way of information dissemination.

Cartoons are representational or symbolic drawings which sometimes combines textual contents culled from news items to make its information more lucid, credible and understandable. Untoward behaviours like corruption, insurgency, terrorism, nepotism, debauchery, rape, banditry and brigandage among other vices are regularly featured in cartoons. This is an attempt by cartoon artists to communicate to the public about the dangers of illicit activities to individuals and how it could jeopardise the prospects of society. A cartoon, like any other media, is described as an essential aspect of human interaction. It is fundamental to the growth of any society because a good system of communication enables people to exchange symbols and propagate learning at a faster rate. (McBride et al., 1981). Moreover, Burgron and Ruffener (1978) see communication generally as transactional, affective, personal, instrumental and consummatory in the sense that both the source and the receiver are always having an impact on each other through symbolic behaviour. 


\section{Cartoon as communication}

According to Apkon (2013), visual images are largely seen in our contemporary world. Various forms of visual culture surround us. These include photographs, TV programs, advertisements, newspapers layout, paintings and the art of caricature or cartoons. Furthermore, Apkon (ibid) in his book 'The Age of the Image' noted that images are powerful because of the physiology of our brains that make the act of seeing a constant creative experience. Visual images stir the mentality and highlight different semantic inferences.

Cartoons, in particular, as stated by Cohn, Taylor-Weiner, \& Grossman (2012), is a universal means of communication and expression in which cultural symbolism is represented. In specific, the visual language of cartoons in general and political cartoons offers the viewer with a chance to interpret it from various perspectives as it communicates. Communication, as defined by Douglas (2013), is 'the act of conveying the intended meaning to another entity through the use of signs and semiotics rules'. The steps of communication, according to Shannon-Weaver's model of communication include a sender, encoder, channel, decoder, receiver and feedback. Consequently, this implies that there is a source of the information which transmits the message intended through a medium such as an internet, social media, and print.

On the importance of communication, MacBride et al. (1981) comment that

"Communication maintains and animates life. It is also activity and civilization; it leads people and peoples from instinct to inspiration; through variegated processes and system enquiry command and control it creates common pool of ideas, strengthens the feelings of togetherness through exchange of messages and translates thought into action reflecting every emotion and need from the humblest tasks of human survival to supreme manifestations of creativity or destruction." The assertion of Hanneman and William (1975) that whatever we do communicate something to others further amplifies the importance of communication. Therefore, communication is a means of facilitating social integration and cohesion in society, and it takes place in various forms and at different levels.

Michael and Michael (1978) further explains that

i. Communication is transactional: This is because of all interactive signals in a communication framework impact on the sender and the receiver automatically and simultaneously.

ii. Communication is effective: This suggests that our emotional responses (subjective evaluations) affect the way communication is exchanged.

iii. Communication is 'personal' in the sense that the meanings attached to it exist in the participants and not in the non-verbal symbols we employ in communicating. However, participants can understand each other (or one another) because of the shared codes or verbal and non - verbal symbols, or what Melvin De Fleur (1958) would call "significant symbol".

iv. Communication becomes "instrumental" when we use it, as we often do, as a tool to control our environment and to affect or influence other people.

It is also significant to note that cartoons provide a lot of information that is valuable and richer than what the artist can express in words, This is because the artist will be interpreted by the recipients exactly the way each recipient perceive the illustrated message.

\section{Political Cartoons}

Burns (2016) state that political cartoons are a uniquely revolutionary thought. They may not have the intellectual depth of a revolutionary speech or manifesto, but their easily digestible messages are potent tools for spreading ideas and allowing revolutions to go viral in the new age of internet-fueled activism.

Consequently, political cartoons had a tremendous impact on the way history has unfolded, particularly before the majority of the populations were able to read. Political cartoons are popular because people with minimal reading abilities could understand and relate to a format that communicated powerful ideas in a humorous way.

Mostly, political cartoons are rendered naturally in satirical forms. This is an attempt to criticise the socioeconomic misdeeds and make it a platform that can keep the nation and its leaders on their toes without necessarily communicating in many words. Cartoons are used to explain the depth of immorality in leadership and society such that readers can capture accurately the communicated message that may not have been written in words. The craftsmanship and dexterity of graphic language distinguish a cartoonist from other creative artists.

\section{Methodology}

For this critique, the researchers purposively selected three cartoons from the internet. The choice of choosing these three cartoons is based on the researcher's discretion. 


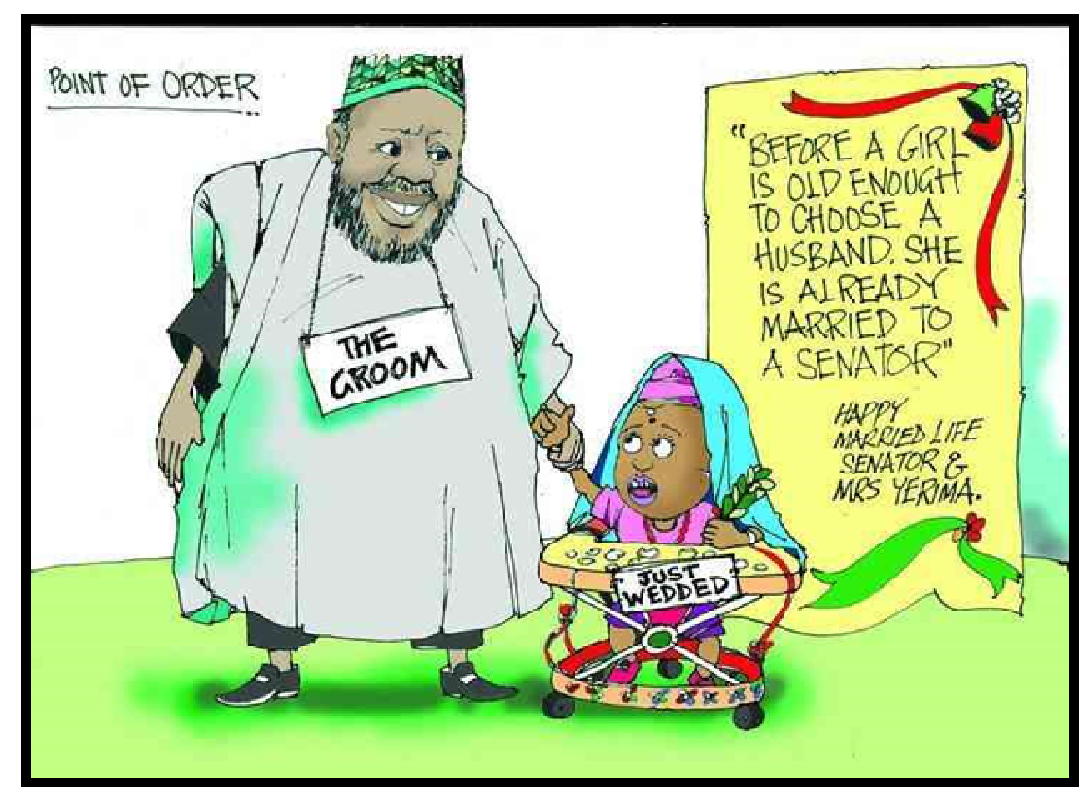

Figure 1: Point of Order. (2013). Cartoon showing Senator Yerima's Wedding with a minor.

(Source: chikaodu ahblog.com)

A Nigerian Senator was reported to have married a 13-year-old Egyptian minor in June 2013. The news was reduced with a rude shock in a country where the constitution has set 18 years as the minimum voting or driving age. It was considered an abuse; therefore, when underage is handed over to a man who is old enough to be a grandfather to the 13-year-old girl. The cartoonist rendering of the news item in visual form has set an agenda of discourse for the reading public to engage the government to ensure compliance to the stipulations of the constitution and discourage tendencies of using the Ahmed Yerima experience to force child marriage into our nationhood especially when it is coming from a distinguished lawmaker and a former governor who has fathered a girl like the "Egyptian minor victim". The cartoon came as a response to an outrage that greeted the endorsement of the Senate of the federal republic of Nigeria that threw its weight behind the action of the senator with the readiness to amend the constitution to favour such practices in the future. Aside from the public outcry against the immoral outlook of the act and its perceived illegality, there were petitions from bloggers denouncing the nuptials. Yerima justified his action by claiming that he has not violated any known sharia law. Under Nigeria's national Child Rights Act of 2003, the legal age for anyone to get married is 18 . However, there are national and international laws protecting children from sexual exploitation and trafficking. The cartoon typifies a socio-cultural absurdity, constitutional illegality as well as legislative rascality. The artist creates an opportunity for the public to see realities that may not be visible through news reports with the dexterity of a visual illustrator.

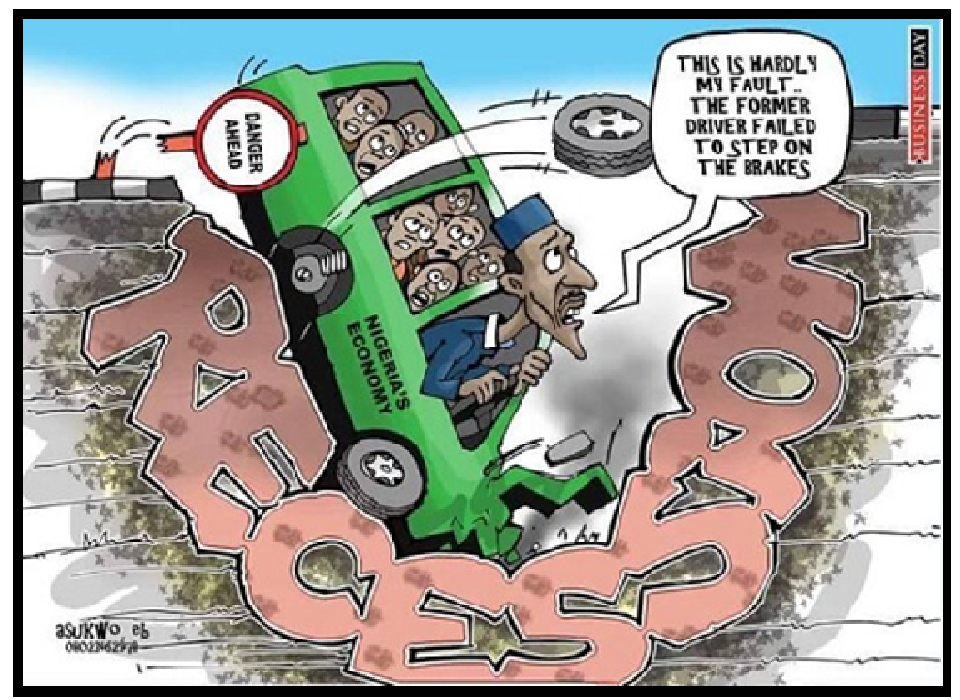

Figure 2: A cartoon depicting the recession experience in Nigeria. (2017). Source: https://Jeocity.com/the-way-forward-on-nigeria-economic-recession/ 
The artist's portrayal of the recession experience of the Nigerian state as a sinking van in the muddy waters of poor economic policies is a reflection of the creative thoughts of the cartoonist which revealed how the power of the pen and colours can offer clarity of issues to the segment of the public that can interpret visual language especially when cartoons are rendered in the most effective way.

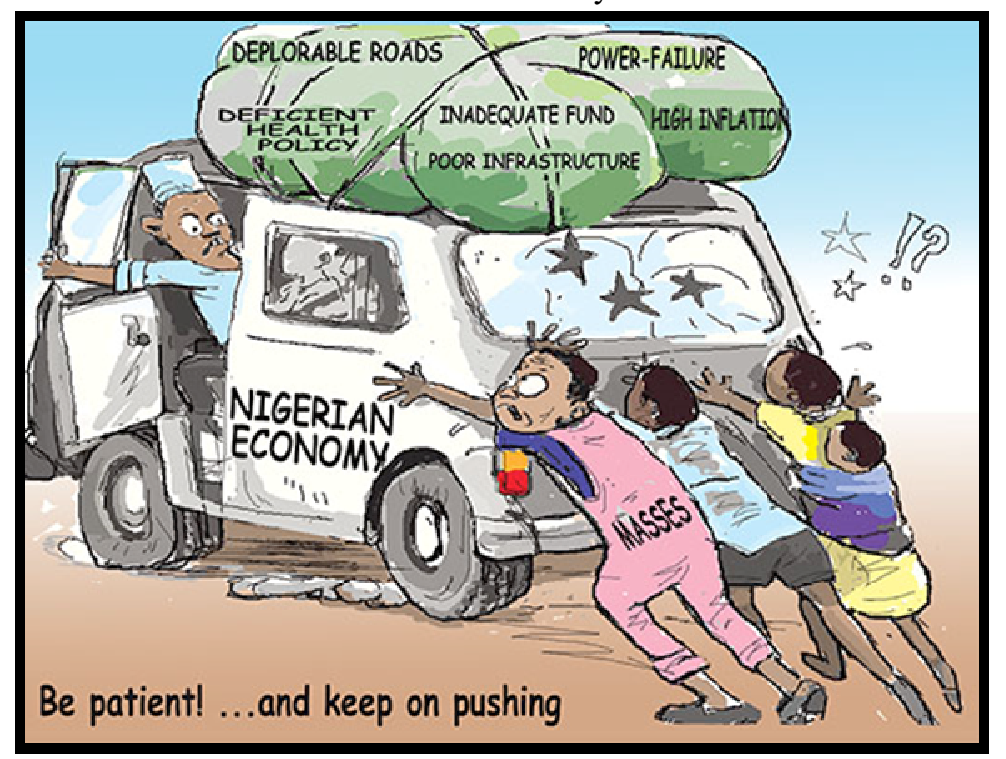

Figure 3: A cartoon depicting Nigeria going through hard times. (2014)

Source: www.ifeadebayo.com/nigerias-biggest-problem/what is Nigeria's biggest problem?

The cartoon on hard times in Nigeria reveals the peak of tyranny and oppression when the victims of the failure of leadership are compelled to bear the brunt and consequences of failed leadership. The cartoonist captured the mood of the oppressed public being put to a more severe task by the ruling elites with little or no humanity left in the ruling class to provide palliatives for their victims. The government continues to preach patience to the citizens with little or no hope in sight. The cartoon artist created a balance in the visuals by including men and women in the equation.

In the above discussions of the cartoons presented, in this paper, it is significant to see how the cartoonist created a nexus between humour, education and enlightenment to the delight of the reading audience at the same time. An average newspaper reader does not have the time to read all the materials and stories in the newspapers but can quickly pick the visual messages in the cartoons.

\section{Views on influences of cartoons in contemporary times in the light of new media}

Consumers were requested to indicate their opinions on cartoons that reflect and communicate to them with essential communication values. Below is a summary of their views.

- Sometimes, it is challenging for illiterates to understand the imports of certain messages, especially when they are not familiar with symbols embedded in the visuals.

- Editors should duly check the content of cartoon messages as they tend to undermine the reading audiences capacity to interpret highly philosophical and academic contents.

- The cartoonists should desist from using foreign pictures to illustrate to readers who do not share such symbolic language.

- Its persuasive appeal can be very weak if the cartoonist is weak in the ability to render images effectively.

\section{Conclusion}

Cartooning is an old communication pattern that had evolved to strengthen and reinforce the regular newspaper reports in very significant ways. Many recipients of cartoon news have been able to make a lot of sense out of the cartoon art genre in the way news reports are captured and rendered with the skills of satire and profound humour. It is needful to encourage upcoming artists to develop cartooning skills, especially at a time when technology is all around us to help achieve profound styles in the rendition of cartooning of events.

\section{References}

Alimi, A. O.(2015). Effects of Communication Design Elements on Telecom Products in Ibadan M. Tech Thesis, Department of Fine and Applied Arts, Ladoke Akintola University of Technology, Ogbomoso. 
Alimi, A.O. (2004) “ Communication in Outdoor Advertising: Role and Prospects: Symphony - Journal of Arts and Aesthetics vol 4.

Alimi M.M. Communicating Through Cartoons. A psycholinguistic study of the Language of Cartoons in Some Nigerian Newspaper: unpublished Ph. D. Thesis. University of Ibadan 1986.

Bertoline, G.R., Wiebe E.N. and Miller C.L. (1998) Fundamentals of Graphics Communication, $2^{\text {nd }}$ Edition, Pennsylvania: McGraw-Hills

Burgoon, M. and Ruffner, M. (1978). Human Communication: An Introduction. New Jersey: Holt, Rinehart and Winston Press.

Cohn, Taylor-Weiner, \& Grossman (2012). Framing Attention in Japanese and American Comics: CrossCultural Differences in Attentional Structure

Douglas, H. (2013). Communication in Online Etymology Dictionary. https://en.wikipedia.org/wiki/online_Etymology_Dictionary

Hanneman, J. G. and William, J.M. (1975). Communication and Behaviour, Philippines: Wesley Publishing Co. Inc

Parkinson, M.(2011). ThePower of Visual Communication http://www.billiondollargrap.cominfographicsht.com Messaris, P. (1997). Visual Persuasion: The Role of Images in Advertising: London, Sage Publications.

Michael B. and Michael R (1978) Communication Today MacDraw Hill NY

Macbride, S; Abel, E and Omu F. I. A. Many voices, one world: communication and society, Today and Tomorrow Ibadan University press and Parris: The VNESCO Press. 